\title{
МЕТОДИЧЕСКИЕ ПОДХОДЫ К РАЗРАБОТКЕ И ОЦЕНКЕ КАЧЕСТВА НОВЫХ НАПИТКОВ ГРУППЫ «ДИСТИЛЛЯТЫ». Часть 2. ВЫБОР СЫРЬЯ
}

\author{
Е. Ю. Егорова, Ю. В. Мороженко
}

Устойчиво высокий спрос российских потребителей на напитки группы дистилляты мотивирует производителей к увеличению объемов их выпуска, зачастую в ущерб индивидуальности, а порой - и в ущерб безопасности спиртосодержащей продукции. Эта практика приводит к появлению на потребительском рынке напитков низкого качества и откровенных фральсификатов, что свидетельствует об использовании не соответствующего сырья либо несоблюдении режимов его переработки на отдельных стадиях производства.

Целью статьи являлась разработка общих рекомендаций к выбору сырья, используемого в производстве напитков группы «Дистилляты». По результатам обобщения требований действующих нормативных документов, литературных и собственных данных в области технологии производства спиртосодержащих напитков авторами сфрормулированы принципиальные требования, которым должно соответствовать растительное сырье, этиловый спирт и вода, как основные компоненты, используемые при получении напитков группы «Дистилляты».

Ключевые слова: ликероводочные изделия, дистилляты, технология, разработка, растительное сырье, требования к сырью, качество спирта, качество воды.

Как было отмечено ранее, индивидуальность напитков группы «Дистилляты» - коньяков, бренди, виски, рома, водки, джина, кальвадоса, абсентов, горьких настоек и других - обусловлена не только специфичностью технологии, но и грамотным подходом к выбору основного и дополнительного сырья, причем подбором направленным, обеспечивающим качество и дегустационную узнаваемость этих напитков [1, 2].

Рынок напитков-дистиллятов стабильно оценивается как очень перспективный. Емкость этого сегмента потребительского рынка составляет порядка 150-170 млн. дм³/год [3]. Устойчиво высокий спрос российских потребителей на крепкие напитки мотивирует производителей на увеличение объемов их выпуска, зачастую в ущерб индивидуальности, а порой - и в ущерб безопасности продукции. Эта практика приводит к появлению на потребительском рынке напитков низкого качества и откровенных фральсификатов, что свидетельствует как о нарушении технологического процесса на этапах приемки и подготовки сырья, так и о несоблюдении режимов его переработки на отдельных стадиях производства.

Целью данной статьи является разработка общих рекомендаций к выбору сырья, используемого в производстве напитков группы «Дистилляты».
Растительное сырье. Основной технологический интерес при производстве алкогольных напитков представляют водо- $и$ спирторастворимые экстрактивные вещества растительного сырья. Приоритет отдаётся пряно-ароматическому сырью и определенным видам лекарственно-технического сырья, ценность которого определяется повышенным содержанием полифенолов и эфирных масел. Чаще всего именно различием в составе предусмотренного рецептурой растительного сырья и соотношением его ингредиентов обусловлены выявляемые различия во вкусе, цвете и аромате напитков-дистиллятов.

При производстве многокомпонентных напитков рассматриваемой группы, особенно таких, как бальзамы и биттеры, достаточно часто используются кедровый и мускатный орех; плоды черёмухи, шиповника и рябины; ягоды черники и черной смородины; цветки ромашки и календулы; трава эстрагона, мяты, душицы, тысячелистника и полыни; гвоздика, имбирь, мускатный орех; многие другие виды плодово-ягодного, травянистого и пряноароматического сырья. Для производства напитков-дистиллятов крайне важно знать химический состав сырья, приемлемость его органолептических свойств, технологические свойства и особенности поведения в ходе технологического процесса (например, скорость перехода полифенольных соединений 


\section{Е. Ю. ЕГОРОВА, Ю. В. МОРОЖЕНКО}

и эфирных масел в водно-спиртовые растворы разных концентраций); эти параметры могут изменяться в зависимости от года вегетации сырья и срока хранения до переработки. Данные о химическом составе позволяют выделить характерные компоненты, обусловливающие органолептические свойства напитков; знание технологических характеристик сырья позволяет выбрать оптимальные технологические режимы его обработки. Умение целенаправленно использовать эти данные дает возможность создавать многочисленные комбинации растительного сырья при разработке рецептур и прогнозировать органолептические свойства новых напитков.

Растительное сырье используется в качестве источника компонентов, определяющих, прежде всего, вкусо-ароматические характеристики напитков-дистиллятов. В частности, состав и содержание летучих и нелетучих компонентов являются свидетельством аутентичности напитков этой группы [1, 4]. Соответственно, от качества сырья, степени его «свежести» и технологических характеристик зависят и скорость достижения желаемого эффректа (полнота извлечения и преобразования целевых компонентов), и стабильность дегустационных характеристик напитков из разных партий однородной продукции.

Наиболее активными в реакциях окисления на стадии выдержки напитков-дистиллятов являются полифенолы, способные уже в малых концентрациях влиять на вкус и аромат напитков. В одних условиях, например, при получении экстрактов и купажей, это влияние дает положительный эффект и ведет к формированию сложного и индивидуального букета напитка, в других - напротив, возможно непрогнозируемое искажение вкуса и аромата.

Преимущественным способом заготовки сырья, принятым в пищевой промышленности, считается высушивание. Современные щадящие методы сушки позволяют обеспечить сохранение полифенольных соединений, эфирных масел и иных ценных компонентов растительного сырья на достаточно высоком уровне. Однако в зависимости от выбранной технологии сушки, высушенное сырье может различаться по остаточной влажности и, соответственно, целевым характеристикам получаемых из него экстрактов.

Многие виды сушеного травянистого и пряно-ароматического сырья российскими нормативными документами стандартизируются либо по сумме экстрактивных веществ, либо по содержанию компонента(ов), имею- щего(их) наиболее важное значение при промышленной переработке - сумме дубильных веществ, содержанию эфирного масла либо определенного класса флавоноидов и др.

Плодово-ягодное сырье, используемое в производстве напитков, контролируется, как правило, только по показателям, характеризующим его доброкачественность для переработки на предприятиях пищевой отрасли. Однако некоторые компоненты плодов и ягод, не зависящие непосредственно от показателей доброкачественности, также могут влиять на качество напитков. Необходимо отметить, что в технологии напитковдистиллятов растительное сырье нередко выполняет не только функцию естественного «ароматизатора». Повышенное содержание нерастворимых пищевых волокон, свойственное отдельным видам сырья (кедровый орех, семена многих пряностей, высушенные плоды и цветки, и т. п.), позволяет на стадии экстракции или мацерации в определенной степени «облагородить» получаемый напиток: клетчатка и лигнин сорбируют из водноспиртовой смеси токсичные компоненты сивушных масел, нежелательные для получения напитков даже в следовых количествах [5]. Те же пищевые волокна могут адсорбировать и компоненты, ценные для фрормирования букета напитка.

Таким образом, при подборе растительного сырья для получения дистиллятов необходимо учитывать его состав и содержание влаги, уметь прогнозировать оптимальные степень измельчения и гидромодуль - всё это отражается на эфффективности перехода экстрагируемых компонентов в дистиллят.

Для большинства видов растительного сырья (особенно это относится к наиболее популярным в производстве напитков) основные технологические характеристики и закономерности извлечения полифенольных соединений хорошо изучены (таблицы 1-2). Следует также избегать необоснованной многокомпонентности рецептур, учитывая вероятное синергетическое, аддитивное или антагонистическое взаимодействие отдельных видов сырья между собой. Завышенные нормы расхода сырья при составлении рецептуры способны привести как к негативным изменениям во вкусе и аромате напитков, так и к ухудшению их стабильности в хранении.

С учетом вклада в формирование качества напитков-дистиллятов, не менее важное значение имеют вода и спирт. Оба компонента являются основой полуфабрикатов, а готовая продукция содержит до 95-99 \% водноспиртовой смеси. 
Таблица 1 - Технологические характеристики некоторых видов растительного сырья (цитируется по [6])

\begin{tabular}{|l|c|c|c|c|}
\hline \multicolumn{1}{|c|}{ Растительное сырье } & $\begin{array}{c}\text { Влажность } \\
\text { сухого } \\
\text { сырья, \% }\end{array}$ & $\begin{array}{c}\text { Выход экстракта, } \\
\text { г/100 г } \\
\text { сухого сырья }\end{array}$ & $\begin{array}{c}\text { Содержание экс- } \\
\text { трактивных веществ } \\
\text { в экстракте, \% }\end{array}$ & $\begin{array}{c}\text { Коэффрициент } \\
\text { экстрактивности } \\
\text { сухого сырья }\end{array}$ \\
\hline Аир болотный, корень & 9,8 & 27,0 & 15,0 & 0,13 \\
Брусника, ягоды & 11,5 & 16,3 & 4,5 & 0,42 \\
Душица, трава & 8,2 & 26,0 & 23,0 & 0,02 \\
Девяси, корень & 10,2 & 27,0 & 23,5 & 0,11 \\
Зверобой, трава & 7,6 & 15,0 & 21,0 & 0,66 \\
Имбирь, корень & 10,0 & 17,0 & 11,3 & 0,18 \\
Мелисса лекарственная, трава & 8,7 & 24,8 & 16,0 & 0,02 \\
Можжевельник, ягоды & 12,5 & 16,3 & 16,0 & 0,09 \\
Тимьян, трава & 7,8 & 16,5 & 13,0 & 0,12 \\
\hline
\end{tabular}

Таблица 2 - Зависимость содержания в экстрактах экстрагируемых компонентов от температуры экстрагирования и концентрации этанола в экстрагенте (цитируется по [7])

\begin{tabular}{|c|c|c|c|c|c|c|c|c|c|c|c|c|}
\hline \multirow{3}{*}{$\begin{array}{c}\text { Концен- } \\
\text { трация } \\
\text { этанола, } \\
\%\end{array}$} & \multicolumn{12}{|c|}{ Экстракты из ягод } \\
\hline & \multicolumn{3}{|c|}{ черники } & \multicolumn{3}{|c|}{ голубики } & \multicolumn{3}{|c|}{ клюквы } & \multicolumn{3}{|c|}{ брусники } \\
\hline & $30^{\circ} \mathrm{C}$ & $40^{\circ} \mathrm{C}$ & $50^{\circ} \mathrm{C}$ & $30^{\circ} \mathrm{C}$ & $40^{\circ} \mathrm{C}$ & $50^{\circ} \mathrm{C}$ & $30^{\circ} \mathrm{C}$ & $40^{\circ} \mathrm{C}$ & $50^{\circ} \mathrm{C}$ & $30^{\circ} \mathrm{C}$ & $40^{\circ} \mathrm{C}$ & $50^{\circ} \mathrm{C}$ \\
\hline \multicolumn{13}{|c|}{ Дубильные вещества, мг/100 г } \\
\hline 30 & 0,18 & 0,21 & 0,24 & 0,30 & 0,35 & 0,38 & 0,10 & 0,10 & 0,12 & 0,11 & 0,13 & 0,14 \\
\hline 60 & 0,23 & 0,27 & 0,30 & 0,39 & 0,43 & 0,47 & 0,12 & 0,14 & 0,1 & 0,14 & 0,17 & \\
\hline 96 & 0,17 & 0,19 & 0,21 & 0,26 & 0,30 & 0,34 & 0,09 & 0,10 & 0,11 & 0,10 & 0,11 & 0,13 \\
\hline \multicolumn{13}{|c|}{ авоноиды (в пересчете на рутин), мг/100 г } \\
\hline 30 & 422 & 430 & 444 & 684 & 726 & 764 & 549 & 574 & 586 & 262 & 280 & 289 \\
\hline 60 & 307 & 313 & 330 & 529 & 534 & 536 & 394 & 416 & 425 & 194 & 201 & 204 \\
\hline 96 & 198 & 200 & 204 & 331 & 341 & 349 & 265 & 269 & 280 & 119 & 121 & 124 \\
\hline
\end{tabular}

Этиловый спирт. Спирт играет роль основного участника в процессах получения классических напитков-дистиллятов - коньяков, виски, кальвадоса и рома, обогащенных в процессе выдержки летучими и нелетучими продуктами этанолиза и гидролиза полифенолов дубовой древесины [8-11]. В качестве альтернативы дубу при получении новых напитков-дистиллятов изучается возможность использования древесины плодовых культур (например, сливы и вишни) и скорлупы кедровых орехов, либо экстрактов с характерным для дистиллятов набором ароматических альдегидов и фенолокислот [3-5].

Вид исходного сырья при получении спирта и выбранные параметры дистилляции также относятся к ведущим фракторам, определяющим качество спирта и органолептические свойства будущих напитков посредством фрормирования специфичного набора ароматобразующих компонентов, накапливающихся в бражке и спирте на стадиях сбраживания и дистилляции $[8,12$, 13]. В технологии дистиллятов используются виноградный, сахаро-тростниковый, зерновой или фрруктовый дистиллят, либо спиртректификат питьевого качества, существенно различающиеся между собой по содержанию органических компонентов (таблица 3). Доля спирта в готовом напитке может достигать 52-60 \% (джин, коньяк, виски) и даже 75-86 \% (абсен- ты), поэтому от качества этилового спирта напрямую зависят и дегустационная индивидуальность, и безопасность получаемых напитков для потребителя.

Основные характеристики этилового спирта, учитываемые при получении рассматриваемых напитков в условиях производства, - содержание метанола, остаточное содержание эфриро-альдегидной фракции и компонентов сивушных масел, массовая концентрация сухого остатка и проба на окисляемость [16]. Исследования показывают, что чем выше содержание сухого остатка в используемом спирте (что более характерно для спирта с $\mathrm{pH} 7,8-9,0)$, тем ниже результаты дегустационной оценки спирта и приготовленных на его основе напитков. При pH спирта на уровне 7,8-9,0 содержание сухого остатка в нем может достигать $24 \mathrm{mr} /$ дм$^{3}$.

Состав соединений, сопутствующих этанолу, зависит от качества дистилляции. В составе этилового спирта разного качества обнаружено более 200 соединений, концентрацию которых очень сложно установить стандартными методами анализа. Несмотря на то, что их содержание, как правило, близко к следовым количествам (от $10^{-5}$ до $10^{-9} \%$ ), их влияние на органолептическую оценку может быть достаточно значимым. Так, присутствующие в спирте сложные эфиры высших жирных кислот придают ему 
слабый фрруктовый запах. Присутствие в спиртедистилляте простых эфиров или высших спиртов является одной из причин появления характерной горечи и слабого прогорклого запаха.
Присутствие высших спиртов ведет также к снижению показателя окисляемости спирта (на 57 минут) и особой «жгучести» вкуса [2].

Таблица 3 - Требования НД к дистиллятам и спирту-ректификату (выдержка)

\begin{tabular}{|c|c|c|c|c|}
\hline \multirow[t]{3}{*}{ Наименование показателя } & \multicolumn{4}{|c|}{ Значение показателя согласно требованиям НД } \\
\hline & \multicolumn{2}{|c|}{ ГОСТ 31728-2014 [14] } & \multirow{2}{*}{$\begin{array}{c}\text { ГOCT P } 55799 \\
-2013[15] \\
\end{array}$} & \multirow{2}{*}{\begin{tabular}{|r|} 
ГОСТ 5962 \\
$-2013[16]$ \\
\end{tabular}} \\
\hline & молодой & выдержанный & & \\
\hline Аромат & $\begin{array}{c}\text { Сложный, с } \\
\text { винными } \\
\text { тонами и } \\
\text { легкими } \\
\text { цветочны- } \\
\text { ми оттен- } \\
\text { ками }\end{array}$ & $\begin{array}{c}\text { Сложный, с вин- } \\
\text { ными тонами, с } \\
\text { тонами древеси- } \\
\text { ны дуба и оттен- } \\
\text { ками от цветочно- } \\
\text { плодово- } \\
\text { ванильных до } \\
\text { пряно-шоколадно- } \\
\text { смолистых }\end{array}$ & \multirow[t]{2}{*}{$\begin{array}{c}\text { Характерные } \\
\text { для дистилля- } \\
\text { та, вырабо- } \\
\text { танного из } \\
\text { соответству- } \\
\text { ющего зерно- } \\
\text { вого сырья, } \\
\text { без посторон- } \\
\text { него привкуса } \\
\text { и запаха }\end{array}$} & \multirow{2}{*}{$\begin{array}{c}\text { Характерные } \\
\text { для этилового } \\
\text { ректификован- } \\
\text { ного спирта кон- } \\
\text { кретного наиме- } \\
\text { нования, выра- } \\
\text { ботанного из } \\
\text { соответствую- } \\
\text { щего сырья, без } \\
\text { привкуса и за- } \\
\text { паха посторон- } \\
\text { них веществ }\end{array}$} \\
\hline Вкус & $\begin{array}{l}\text { Чистый, } \\
\text { винный, } \\
\text { жгучий }\end{array}$ & $\begin{array}{c}\text { Чистый, винный, } \\
\text { от жгучего до мяг- } \\
\text { кого, гармонично- } \\
\text { го, с тонами дре- } \\
\text { весины дуба } \\
\end{array}$ & & \\
\hline Объемная доля этилового спирта, \% & $62,0-70,0$ & $55,0-70,0$ & не более 94,8 & $96,0-96,3$ \\
\hline Проба на чистоту с серной кислотой & \multicolumn{3}{|c|}{ Не нормируется } & Выдерживает \\
\hline $\begin{array}{l}\text { Проба на окисляемость, мин, } \\
\text { при } 20^{\circ} \mathrm{C}, \text { не менее }\end{array}$ & \multicolumn{3}{|c|}{ Не нормируется } & $15-22$ \\
\hline $\begin{array}{l}\text { Массовая концентрация компонен- } \\
\text { тов, мг/100 см }{ }^{3} \text { безводного спирта: } \\
\text { - высших спиртов }\end{array}$ & $180-600$ & $170-500$ & \multicolumn{2}{|c|}{ (в составе сивушного масла) } \\
\hline $\begin{array}{l}\text { - альдегидов / } \\
\text { уксусного альдегида, не более }\end{array}$ & $3,0-50,0$ & $\begin{array}{l}5,0-50,0 \\
\text { Не нормируется }\end{array}$ & $1,0-35,0$ & $\begin{array}{c}\text { Не нормируется } \\
0,2-0,5\end{array}$ \\
\hline - эфириов & $50-250$ & $50-270$ & $5-150$ & Не более $0,5-1,3$ \\
\hline $\begin{array}{l}\text { - летучих кислот, не более / } \\
\text { свободных кислот, не более }\end{array}$ & 80 & $\begin{array}{l}200 \\
\text { Не нормируется }\end{array}$ & \multicolumn{2}{|c|}{ Не нормируется } \\
\hline $\begin{array}{l}\text { - фрурфурола, не более } \\
\text { - сивушного масла }\end{array}$ & $\begin{array}{l}3,0 \\
\mathrm{He} \mathrm{H}\end{array}$ & $\begin{array}{r}3,0 \\
\text { ормируется }\end{array}$ & $\begin{array}{c}3,0 \\
50-600 \\
\end{array}$ & $\begin{array}{l}\text { Не допускается } \\
\text { Не более } 0,5-0,6\end{array}$ \\
\hline $\begin{array}{l}\text { Массовая концентрация метилового } \\
\text { спирта, г/дм³ (\% об.), не более }\end{array}$ & 1,0 & 1,0 & $(0,05)$ & $(0,003-0,005)$ \\
\hline $\begin{array}{l}\text { Массовая концентрация общего } \\
\text { экстракта, г/дм³ }{ }^{3} \text { не менее }\end{array}$ & $\begin{array}{l}\text { Не норми- } \\
\text { руется }\end{array}$ & 0,7 & \multicolumn{2}{|c|}{ Не нормируется } \\
\hline
\end{tabular}

Содержание названных примесей зависит от отбираемой фрракции при получении спиртадистиллята. Особенно это важно при получении спирта и напитка в условиях одного производства. С учетом изложенного выше, важное значение для получения дистиллятов - виноградных, зерновых или плодовых - с требуемым составом летучих компонентов имеет правильное определение начала отбора головной фракции дистиллята [8, 12].

Вода. Вода и водные растворы этилового спирта являются основными компонентами на стадии приготовления водно-спиртовых настоев и экстрактов растительного сырья. Вода может вводиться в состав напитка как на начальных, так и на завершающих стадиях технологического процесса.

Особое значение имеет минеральный состав используемой воды, также оказывающий влияние на дегустационные качества напитков.
Так, ионы кальция и магния в низких концентрациях подчеркивают полноту вкуса, гидрокарбонат кальция несколько смягчает вкус и уменьшает «жгучесть» этанола в напитках; бикарбонаты, имеющие высокую буферность и частично нейтрализующие кислотность, могут привносить в напиток грубые и горькие оттенки, заглушающие остальные тона во вкусе напитка [17].

В зависимости от выбранной технологии производства, общий расход воды на $1 \mathrm{~m}^{3}$ напитка может составлять от $15 \mathrm{~m}^{3}$ до $25 \mathrm{~m}^{3}$. В условиях пищевого производства значительные объемы воды расходуются на обеспечение производственных процессов - для мойки и дезинфекции производственных емкостей, трубопроводов, тары и другого. Поэтому на результатах органолептической оценки напитков будет отражаться и наличие нетипичных примесей, случайно попавших в напиток на разных стадиях технологического процесса - дезинфицирующих ПОЛЗУНОВСКИЙ ВЕСТНИК № 22018 
средств, токсинов микробиологического происхождения, компонентов материалов оборудования и используемых в производстве вспомогательных средств, и т. д.

Суммируя всё вышеизложенное, можно выделить ряд общих рекомендаций, которые следует соблюдать при выборе сырья как при создании новых рецептур и технологий, так и для совершенствования технологий уже существующих напитков-дистиллятов:

- детально анализировать данные о химическом составе растительного сырья, с целью грамотного комбинирования и исключения эффектов антагонизма и взаимного усиления его компонентов между собой уже на стадии разработки напитка-дистиллята;

- от партии к партии контролировать влажность растительного сырья для правильного расчета параметров экстракции;

- варьировать фрракциями спиртадистиллята для подбора оптимального состава и соотношения летучих компонентов;

- соблюдать оптимальные условия экстрагирования растительного сырья;

- контролировать качество водоподготовки и чистоту технологического оборудования, контактирующего с водой, спиртом, полуфабрикатами и готовой продукцией.

Нельзя не отметить особую роль интуиции разработчиков в определении наиболее удачного соотношения растительного сырья в рецептурной композиции напитка. Однако для успешной конкуренции напитков-дистиллятов на потребительском рынке необходим, прежде всего, научнообоснованный подход в производственнотехнологических решениях.

\section{СПИСОК ЛИТЕРАТУРЫ}

1. Егорова, Е. Ю. Методические подходы к разработке и оценке качества новых напитков группы «Дистилляты». Часть 1. Разработка технологии нового напитка / Е. Ю. Егорова, Ю. В. Мороженко // Ползуновский вестник. - 2016. - № 3. - с. 4-8.

2. Егорова, Е. Ю. Производство бальзамов и сиропов / Е. Ю. Егорова, М. Н. Школьникова, М. В. Гернет и др. - СПб. : Профессия, 2011. - 408 с.

3. Новикова, И. В. Интенсивные технологии алкогольных и функциональных безалкогольных напитков на основе солодов и экстрактов : сырьевые источники, прогнозирование качества и проектирование рецептур: дисс. ... д-ра техн. наук / И. В. Новикова. - Воронеж, 2015. - Т. 1. $-281 \mathrm{c}$.

4. Егорова, Е. Ю. Ароматические альдегиды экстрактов растительного сырья, используемого в производстве ликероводочных изделий / Е. Ю. Егорова, Д. Ю. Сысоева, Е. Д. Рожнов, Ю. В. Мороженко // Ползуновский вестник. -2014. - № 4. - Т. 2. - с. 126-131.

5. Егорова, Е. Ю. Скорлупа кедрового ореха в производстве алкогольных и безалкогольных напитков / E.
Ю. Егорова, В. В. Будаева, А. А. Лобанова, С. Г. Ильясов // Пиво и напитки. - 2005. - № 5. - с. 44-46.

6. Гореликова, Г. А. Оценка качества и безопасности растительного сырья при производстве функциональных продуктов / Г. А. Гореликова, В. М. Позняковский, Н. Г. Бабанская // Хранение и переработка сельхозсырья. - 2009. - № 6. - с. 40-42.

7. Кравченко, С. Н. Влияние технологических условий на эффрективность извлечения сухих растворимых веществ из плодов семейства Vacciniaceae / C. Н. Кравченко, А. М. Попов // Хранение и переработка сельхозсырья. - 2009. - № 6. - с. 45-47.

8. Скурихин, И. М. Химия коньяка и бренди / И. М. Скурихин. - М. : ДеЛи принт, 2005. - 296 с.

9. Caldeira, I. Sensory and chemical modifications of wine-brandy aged with chestnut and oak wood fragments in comparison to wooden barrels / I. Caldeira, A. P. Belchior, S. Canas et. al. // Analytica Chimica Acta. - 2010. - V. 660. - № 1-2. - p. 43-52.

10. Бурачевский, И. И. Происхождение, классификация и технология приготовления виски / И. И. Бурачевский, Е. В. Воробьева, О. В. Веселовская, Л. П. Галлямова // Производство спирта и ликероводочных изделий. 2013. - № 1. - с. 9-14.

11. Блягоз, А. Р. Химический состав яблочных дистиллятов, выдержанных на черешчатом и скальном дубе / А. Р. Блягоз, Н. М. Агеева // Виноделие и виноградарство. - 2013. - № 5. - с. 32-34.

12. Песчанская, В. А. Сравнительная характеристика способов производства зерновых дистиллятов / В. А. Песчанская, Е.В.Дубинина, Л. Н. Крикунова // Пиво и напитки. - 2015. - № 6. - с. 40-43.

13. ГОСТ 33880-2016. Напитки спиртные. Термины и определения. - Введ. 2017-08-01. - М. : Стандартинфором, 2016. - IV. $-11 \mathrm{c}$.

14. ГОСТ 31728-2014. Дистилляты коньячные. Технические условия. - Введ. 2016-01-01. - М. : Стандартинформ, 2015. - II. -5 c.

15. ГОСТ Р 55799-2013. Дистиллят зерновой. Технические условия. - Введ. 2015-07-01. - М. : Стандартинфором, 2014. - II. -5 c.

16. ГОСТ 5962-2013. Спирт этиловый ректификованный из пищевого сырья. Технические условия. - Введ. 2014-07-01. - М. : Стандартинформ, 2014. - II. -5 c.

17. Борисов, Б. А. Водоподготовка в производстве пищевых продуктов и напитков / Б. А. Борисов, Е.Ю. Егорова, Р.А. Зайнуллин. - СПб. : Профрессия, 2015. - 398 с.

Егорова Елена Юрьевна, д.т.н., профрессор кафредры технологии хранения и переработки зерна ФГБОУВО «Алтайский государственный технический университет им. И.И. Ползунова», 656038, ..Барнаул, ул. Ленина, 46, e-mail: egorovaeyu@mail.ru, тел.: (3852) 29-07-55.

Мороженко Юрий Васильевич, к.Х.н., доцент кафедры биотехнологии Бийского технологического института (фрилиала) ФГБОУ ВО «Алтайский государственный технический университет им. И.И. Ползунова», 659305, г. Бийск, ул.Трофримова, 27, e-mail: uv@bti.secna.ru, тел.: (3854) 43-53-01. 